\title{
BIRDS
}

\section{EASTERN SCREECH-OWL IN MANITOBA: EVIDENCE OF TWENTIETH- CENTURY RANGE EXPANSION}

CHRISTIAN ARTUSO, Bird Studies Canada Manitoba Region, Box 24, 200 Saulteaux Cr, Winnipeg, MB R3J3W3, E-mail: <cartuso@birdscanada.org>

\section{Introduction}

Southern Manitoba to $52^{\circ} \mathrm{N}$ represents the northern range limit of the Eastern Screech-Owl; however, Manitoba may not have been a part of this species' range prior to the late $19^{\text {th }}$ century. ${ }^{20}$ The first confirmed records of the Eastern ScreechOwl in Manitoba are from the early 1920s. Hamilton Laing found this species at Oak Lake in 1921 (specimens CMNAV 17082 and 17193 at the Canadian Museum of Nature), and Norman Criddle recorded screech-owls at Aweme in 1922. ${ }^{19}$ There is no species account for the (Eastern) Screech-Owl in Ernest Thompson Seton's Birds of Manitoba, although he recorded other secretive small owls, e.g. Northern Saw-whet Owl, which he described as a rare resident; Boreal Owl, which he described as a probable resident and winter visitor; and Long-eared Owl, which he described as "tolerably common". ${ }^{21}$ Nonetheless, under the account of the Northern Saw-whet Owl, Seton mentions that R. H. Hunter "claims" to have seen and heard screech-owls in Saboskong Bay and Point du Chêne in 1871, the implication being that Seton treated these records as hypothetical. ${ }^{21}$ The lack of early records of a species that resides in close proximity to humans suggests that screech-owls were either absent or rare in Manitoba in the early $20^{\text {th }}$ century. Taverner concluded that this species was a new arrival, ${ }^{19}$ and others noted an increased density of screech-owls in Manitoba in the 1930s; for example, Rutherford wrote that " $\mathrm{t}] \mathrm{h}$ his 'little horned owl' is becoming increasingly common in the greater Winnipeg district", ${ }^{16}$ and Cartwright stated that they were "now quite common in the timber along the Red and Assiniboine Rivers". ${ }^{5}$ Despite these suggestions, the possibility remains that screech-owls were initially overlooked, perhaps because they were scarce.

Within the last 50 years, Eastern Screech-Owls have expanded their range into the Swan River area of Manitoba as far as $52^{\circ} \mathrm{N}$, from a previous northern limit of ca. $50^{\circ} \mathrm{N}^{23}$ This demonstrates the species' capacity to colonize new areas. There are a few recent records in coniferous or mixed forest in areas such as Bird's Hill Provincial Park and even as far north as the Duck Mountains (single record on 12 April 2002; B. Walley and P. Letain, pers. comm.). An extraordinary extralimital record of a gray adult seen by nine observers occurred on 14 June 1998 at Pisew Falls (above $55^{\circ} \mathrm{N}$; S. Clubb, pers. comm.). It is possible that this species is becoming increasingly adapted to the transition zone between the boreal biome and woodlands of a more deciduous nature. A similar phenomenon has been suggested for Barred Owl, ${ }^{3}$ a species first recorded in Manitoba in 1886, ${ }^{17}$ which may have arrived in the province at a 
similar time as Eastern Screech-Owls, ${ }^{10}$ and whose recent range expansion is well documented and dramatic. ${ }^{13}$

One source of evidence supporting the hypothesis of range expansion may lie in the relative abundance of the color morphs: gray (Fig. 1, see inside back cover), rufous (see front cover), and intermediate or "brown", the former being common in Manitoba while the latter two are rare. This evidence relies on the fact that rufous morph screech-owls are more susceptible to cold temperatures and have a higher mortality, by as much as $40 \%$, when temperatures fall to $-5^{\circ}$ and $-10^{\circ} \mathrm{C} .{ }^{15}$ In northern Ohio, the percentage of rufous birds fell from $23.3 \%$ to $14.7 \%$ in the severe winter of 1951 (lowest temperatures and highest snowfall during a 30 -year study). ${ }^{22}$ Following a record freeze in Texas, rufous birds declined from $8.4 \%$ of the nesting population in 1983 to $4.2 \%$ in 1987 in one study area and from $23.3 \%$ to $16.1 \%$ in another. ${ }^{6}$ Gray plumage contains more melanin than rufous plumage and has better thermoregulatory properties and greater resistance to abrasion by dust particles. ${ }^{6}$, 7, 22 In other polychromatic species, e.g., Ruffed Grouse, gray morph birds also fare better than rufous ones in cold climates. ${ }^{8}$ At the northern limit of their range in Finland, gray morph Tawny Owls constitute $70 \%$ of the population, and gray males have a longer breeding lifespan and higher lifetime recruitment (offspring that survive to breed) than brown males. ${ }^{4}$ Gehlbach noted that although gray owls are more difficult to see in full sunlight, rufous birds are more cryptic in cloudy or humid conditions because red light is filtered out in subdued lighting and is scattered by water vapor. ${ }^{6}$ Because of the nocturnal and crepuscular habits of Eastern Screech-Owls, rufous plumage should be selected for in warm, humid environments. Rufous is dominant to gray genetically because gray $\times$ gray pairings always produce all gray offspring, whereas rufous $\times$ rufous pairing produce ca. $25 \%$ gray young. ${ }^{6,22}$ Based on the evidence of different thermoregulatory properties of rufous and gray plumage, I hypothesized that if the Eastern ScreechOwl had expanded its range into Manitoba, there should have be a decrease in the percentage of rufous birds over time due to lower survivorship.

\section{Methods}

I assembled a database of Eastern Screech-Owl records in Manitoba from 1921 - 2007, and a comparative database from northern Minnesota and North Dakota from 1883 - 2007. Northern Minnesota is defined here as the area above a line across the southern border of Wilkin County to the southern border of Grant - Douglas - Todd - Morrison - Mille Lacs - Kanabec - Pine counties. This corresponds roughly in latitude to the border between North and South Dakota. I chose this area because of its location directly south of Manitoba and because it worked as a convenient unit from where I could assemble a reasonable number of records. Records from southern Minnesota were excluded, as the considerably milder climate there would be predicted to hold a higher percentage of rufous morph screech-owls. The database from northern Minnesota is from a similar set of sources. Care was taken to crossreference all data gathered to ensure that sightings of individual owls were not duplicated. These records were then grouped by decade and the percentage of rufous morph birds calculated per period. Nearly three-quarters (74\%) are sight records from either published sources or from personal communication.

Unfortunately, 783 records (39\% of the database) could not be assigned a color morph either because they were only heard or because this information was not provided. After grouping the 
data by decade, I therefore calculated two percentages: firstly, the number of rufous birds as a percentage of the total number of records of individual birds and secondly the number of rufous birds as a percentage of the total number of records where the morph is clearly specified (hereafter "ms"). Rufous Eastern ScreechOwls are unusual in Manitoba, and to a lesser extent in northern Minnesota and North Dakota, and there is a tendency for observers to report their color, whereas many fail to comment on the color of gray birds. Therefore, the majority of birds in the "morph unknown" category are probably gray. I believe for this reason that the best estimate of the percentage of rufous birds lies somewhere in between the two types of percentages calculated, probably closer to the former (i.e. the lower end). Brown birds are also underreported, as it is difficult to distinguish this intermediate form from gray, even in specimens where intermediate characteristics, feather wear, fading, and foxing (browns become brighter or redder over time) must be considered. In fact, most gray specimens and living screech-owls that I have seen in Manitoba have had a small amount of rufous in the plumage, especially on the tarsi; as a central vertical band through the ear tufts; in the barring and crossbarring on the breast, belly, and flanks (Fig. 2, see inside back cover); or as a subtle wash across the underparts, nuchal collar, mantle, or wing coverts.

The dataset for Minnesota and North Dakota suffers from a very small sample size, in particular from 1940 - 1960. The lower number of records from Minnesota and North Dakota compared to Manitoba is not reflective of lower owl densities but rather of difficulties in collecting data from afar. To compensate for small sample sizes, I averaged the two percentages (rufous morph birds against all individuals and rufous morph birds against individuals where color was specified) as a way of obtaining a fairer means of comparison to the Manitoba data. I also averaged the Manitoba percentages in the same way.

\section{Results}

The Manitoba database consists of over 1700 records representing 1399 individuals from numerous sources including published references, oologists' sets, museum specimens, nest cards, rehabilitated birds, applications for taxidermy permits, Christmas Bird Counts, the Manitoba Nocturnal Owl Survey, and

Table 1. Data sources for Eastern Screech-Owl records in Manitoba, northern Minnesota, and North Dakota from 1886 - 2007 after removal of possible repeat sightings. Numbers in parentheses are percentages of the color morphs against the total for each category. See text for definition of northern Minnesota.

\begin{tabular}{|c|c|c|c|c|c|c|c|}
\hline & Adults & Juveniles & Gray & Brown & Rufous & Unknown & TOTALS \\
\hline \multicolumn{8}{|l|}{ Manitoba } \\
\hline Sight records & 709 & 438 & $785(68.4)$ & $17(1.5)$ & $27(2.4)$ & $316(27.6)$ & 1147 \\
\hline Specimen / dead & 118 & 6 & $95(76.6)$ & $14(11.3)$ & $6(4.8)$ & $9(7.3)$ & 124 \\
\hline Heard only & 93 & 0 & 0 & 0 & 0 & $93(100)$ & 93 \\
\hline Banded or rehab & 1 & 0 & $1(100)$ & 0 & 0 & 0 & 1 \\
\hline Total & 945 & 454 & $887(63.4)$ & $32(2.3)$ & $33(2.4)$ & $445(31.8)$ & 1399 \\
\hline \multicolumn{8}{|l|}{ Northern MN and ND } \\
\hline Sight records & 263 & 81 & $152(44.2)$ & $1(0.3)$ & $32(9.3)$ & $159(46.2)$ & 344 \\
\hline Specimen / dead & 80 & 7 & $59(67.8)$ & $4(4.6)$ & $21(24.1)$ & $3(3.4)$ & 87 \\
\hline Heard only & 175 & 0 & 0 & 0 & 0 & $175(100)$ & 175 \\
\hline Banded or rehab & 5 & 0 & $4(80)$ & 0 & 0 & $1(20)$ & 5 \\
\hline Total & 523 & 88 & $215(35.2)$ & $5(0.8)$ & $53(8.7)$ & $338(55.3)$ & 611 \\
\hline TOTAL & 1457 & 497 & 1053 & 35 & 84 & 780 & 1954 \\
\hline
\end{tabular}




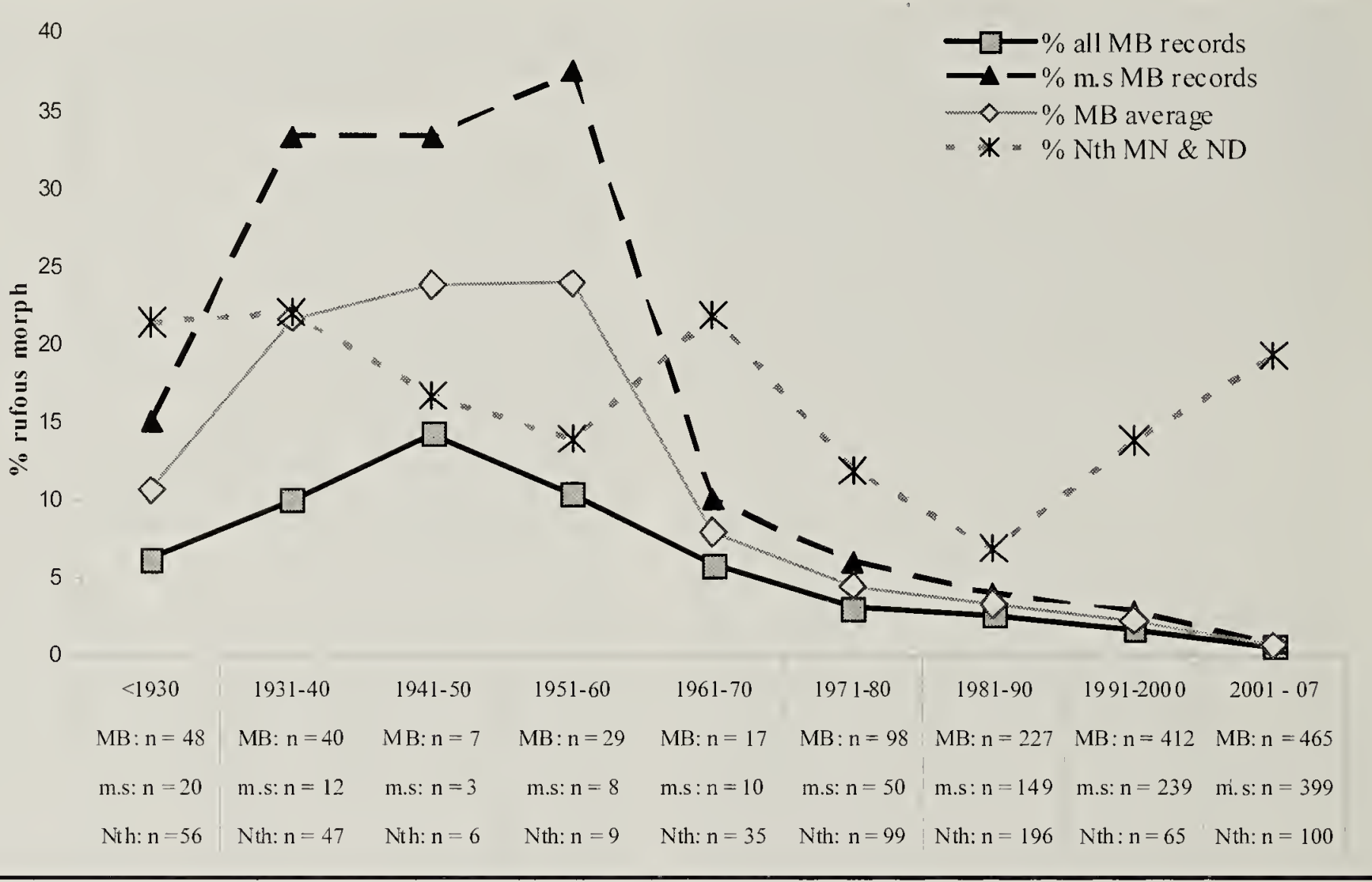

Figure 3. Percentage of rufous morph Eastern Screech-Owls recorded in Manitoba by decade (\% of total number of birds recorded and of total number of records where color morph is specified [ms]) and in North Dakota and northern Minnesota (Nth; average of the \% of total number of birds recorded and of total number of records where morph is specified).

personal communication from observers (Table 1). When the whole database is considered and records where color was not specified (the "Unknown" column) are excluded, $93 \%$ of the Manitoba population is gray and $3.5 \%$ is rufous, whereas in northern Minnesota and North Dakota $79 \%$ are gray and $19 \%$ are rufous (Table 1).

The data suggest that prior to the 1930s, rufous morph birds constituted approximately $6.25-10.63 \%$ (average $\%$ of all records and $\% \mathrm{~ms}$ ) of the Manitoba population. Today $<1 \%$ of Eastern Screech-Owls in Manitoba are rufous (Fig. 3 ). When plotted by decade, rufous morph birds appear to have increased in the period from 1930 - 1960 but then decline steadily and gradually from the 1960 s to 2005 . In northern Minnesota and North Dakota, the percentage of rufous birds appears to have fluctuated considerably but has not otherwise changed greatly between the period prior to $1930(21 \%)$ and the 2001 - 2007 period $(19 \%)$.

\section{Discussion}

The data suffer potential biases such as unequal small sample sizes by period and inconsistency in the ratio of specimens to sight observations and must be treated with caution. The end points of the graph ( $<1930$ versus $2001-2007$ ) suggest different overall trends between Manitoba (a decline in rufous morph birds) and northern Minnesota and North Dakota (minimal change despite some fluctuation). However, problems arise in interpreting trends in the intervening years where sample sizes are small, in particular the period from $1930-1960$, which in Manitoba at least shows an increase in rufous owls. One possible explanation for this increase lies in the 
different data collection practices during and in proximity to WWII, which may have influenced these results. During this period, specimen and egg collecting declined in popularity, and the number of field observations is low. Many of the birds reported from this period were found dead or injured, often in barns or on farmsteads. Since rufous birds are more susceptible to cold, their numbers would be unnaturally inflated by a sample collected in this manner, especially in the small sample available from this period. The data support this contention since the percentage of rufous birds from specimens only for this period is higher than the same percentage calculated from sight records only (Manitoba ms data set: $3.2 \%$ of sight records rufous versus $5.2 \%$ of specimens, U.S. ms data set: $17.3 \%$ of sight records rufous versus $25 \%$ of specimens). Unfortunately, the various types of records in this data set are not evenly distributed, with more specimens in the earlier part of the 20th century and more sight records in the latter half.

The data from the U.S. as presented in Fig. 3 suggest large variation in the percentage of rufous birds by decade. In addition to smaller sample sizes, for the most part, than the Manitoba data, the U.S data include an extremely high number of morph-unspecified records (53\%) compared to the Manitoba dataset $(33 \%)$. Some of the variation in this part of the graph may therefore be a product of data biases, while some of this variation may reflect changes in the survival rates of rufous birds following particularly cold winters. ${ }^{6,22}$ Given the poor suitability of the data for statistical analysis, I cannot be sure if the trends noted are significant.

Unlike the U.S. data, the Manitoba data show a consistent decline in rufous birds for the period where sample sizes are highest $(1971$ - 2007) and, despite the difficulty of interpreting earlier trends, support the hypothesis of a decline in rufous Eastern Screech-Owls in Manitoba to near monochromatism due to their poor suitability to the local climate.

If the Eastern Screech-Owl has extended its range into Manitoba, the most significant factor in this expansion is likely to be anthropogenic habitat change. Larger human settlements have brought with them the planting of trees around homesteads and shelterbelts in areas of prairie grassland formerly inhospitable to a woodland species such as the Eastern Screech-Owl. ${ }^{20}$ Many trees in Manitoba may now be larger than in previous centuries, especially in proximity to human habitation due to watering and heat-island effects. During the $20^{\text {th }}$ century, there have been both increased plant growth at mid- to high latitudes $\left(45^{\circ} \mathrm{N}\right.$ and $\left.70^{\circ} \mathrm{N}\right)$ and a lengthened growing season. ${ }^{24}$ Tree phenology has changed, with some species blooming or budding weeks earlier, ${ }^{24}$ and with some species in southeastern Manitoba becoming hardier. ${ }^{14}$ Larger trees are more likely to produce cavities of sufficient size for screech-owls and the open understory they prefer for hunting. Buildings on the landscape may also have assisted in range expansion, providing both shelter and access to prey, ensuring greater likelihood of winter survival at the range periphery. 1, 9, 23 An additional benefit to Eastern Screech-Owls is the placement of nest boxes (usually for Wood Ducks), which they readily use as nest and roost sites. The earliest record of Eastern Screech-Owls breeding in a nest box in Manitoba is 1928 (nest card).

The current distribution of the Eastern Screech-Owl in Manitoba is somewhat, but not entirely, linked with human settlement. Eastern Screech-Owls have higher population densities in suburban Winnipeg than in rural areas, producing larger broods and beginning breeding 
earlier in the year. ${ }^{2}$ Available habitat in suburbs close to rivers or creeks with mature trees matches many of their habitat selection preferences, including a relatively open subcanopy and middle story, many potential nest sites, some planted conifers (frequently used as roost sites by breeding males), and tall trees with little shrub density below them. ${ }^{2}$ Suburbs also have lower densities of Great-horned Owls and raccoons despite higher densities of domestic cats, ${ }^{2}$ and a greater diversity of prey with access to invertebrate prey earlier in the breeding season. $^{2}$ Only one of 52 nests that I found between 2004 and 2007 was in "wildlands", i.e. <1 human resident per hectare. ${ }^{2}$

Another factor that may have assisted the Eastern Screech-Owl to spread northward is the introduction of certain prey items of Palearctic origin in the late $19^{\text {th }}$ century, in particular the House Sparrow, ${ }^{20}$ which was first recorded in the province in $1892 .{ }^{18}$ The strongest evidence for this is the apparent importance of the House Sparrow and the Rock Pigeon (captured in barns presumably along with rodents) for winter survival in the Dauphin area. ${ }^{23}$ Nonetheless, in the Winnipeg area, no introduced prey item is consumed nearly as frequently as the native Meadow Vole, which comprises $35 \%$ of all vertebrate captures year round and $32 \%$ in winter. The introduced earthworm Lumbricus terrestris (commonly called "night crawler"), often captured in watered lawns and gardens, is summer prey only. ${ }^{2}$ Probably more important to screechowls are concentrations of prey, as may occur around fallen birdseed or at avian communal roosts.

The decline in rufous morph birds in Manitoba over the course of the $20^{\text {th }}$ century from similar percentages to those found in North Dakota and northern Minnesota to near monochromatism today supports the hypothesis of $20^{\text {th }}$-century range expansion into southern Manitoba. In addition to Eastern Screech-Owls, a number of eastern woodland species have apparently undergone similar north or northwestward expansion, including Wood Duck, American Woodcock, Barred Owl, Red-headed Woodpecker, Yellowthroated Vireo, Purple Martin, Goldenwinged Warbler, Eastern Bluebird, and Indigo Bunting, ${ }^{20}$ as well as mammals such as raccoons. ${ }^{12}$ Many of these species have some similar habitat requirements to Eastern Screech-Owls, including cavity nest sites and/or a partially open understory for foraging. Although the causes may differ with individual species, a trend of north and northwestern expansion, possibly coupled with the disturbance of prairie habitat, is implied in the early $20^{\text {th }}$ century in southern Manitoba, and more generally in North America. ${ }^{11}$ The context and mechanisms of range expansion in the northern prairie region therefore warrant further investigation.

\section{Acknowledgments}

I thank Rick Baydack, James R. Duncan, C. Stuart Houston, Rudolf Koes, Nicola Koper, Erkki Korpimäki, Merlin Shoesmith, Peter Taylor, and an anonymous reviewer for their suggestions to improve earlier drafts of this manuscript. I thank the many individuals who contributed to the historical database (named in my thesis). ${ }^{2}$ The following museums provided information on Eastern Screech-Owl specimens in their collections or sightings from record card schemes: The American Museum of Natural History, The Bell Museum of Natural History, The Carnegie Museum of Natural History, The Cornell University Museum of Vertebrates, The Field Museum of Natural History, The Harvard University Museum of Comparative Zoology, The Heritage North Museum (Dauphin, Manitoba), The Manitoba Museum, The Michigan 
State University Museum, The Provincial Museum of Alberta, The Royal Ontario Museum, The Royal Saskatchewan Museum, The Science Museum of Minnesota, The Smithsonian National Museum of Natural History, The Stewart Hay Memorial Museum at the University of Manitoba, The University of Michigan Museum of Zoology, and The Yale Peabody Museum.

1. ADAM, C. I. G. 1989. Eastern Screech-Owl in Saskatchewan and adjacent areas. Blue Jay 47:164-188.

2. ARTUSO, C. 2009. Life on the Edge: The Eastern Screech-Owl in Winnipeg. Ph.D. thesis, University of Manitoba, Winnipeg, MB.

3. BOXALL, P. C. and H. R. STEPNEY. 1982. The distribution and status of Barred OWl in Alberta. Canadian Field-Naturalist 96:46-50.

4. BROMMER, J. E., K. AHOLA, and T. KARSTINEN. 2005. The colour of fitness: plumage coloration and lifetime reproductive success in the tawny owl. Proceedings of the Royal Society B 272:935-940.

5. CARTWRIGHT, B. W. 1931. Notes and observations on some Manitoban birds. Canadian Field-Naturalist 45:181-187.

6. GEHLBACH, F. R. 1994. The Eastern ScreechOwl: Life history, ecology, and behavior in the suburbs and countryside. Texas A\&M University Press, College Station.

7. GILL, F. B. 1995. Ornithology. Second Edition. W. H. Freeman, New York, U.S.A.

8. GULLION, G.W. and W.H. MARSHALL. 1968. Survival of Ruffed Grouse in a Boreal Forest. Living Bird 7:117-167.

9. HOUSTON, C. S. 1989. First fully documented nesting of Eastern Screech-Owl in Saskatchewan. Blue Jay 47:210 -212.

10. HOUSTON, C. S. and K. J. MCGOWAN. 1999. The westward spread of the Barred Owl. Blue Jay $57: 190-195$.

11. JOHNSON, N. K. 1994. Pioneering and natural expansion of breeding distributions in western North American birds. Studies in Avian Biology 15:27-44.
12. LARIVIÈRE, S. 2004. Range expansion of raccoons in the Canadian prairies: review of hypotheses. Wildlife Society Bulletin 32:955-963.

13. MAZUR, K. M. and P. C. JAMES. 2000. Barred Owl. In: Poole, A. and F. Gill (eds.). The birds of North America, no. 508. Academy of Natural Sciences, Philadelphia, and The American Ornithologists' Union, Washington, D.C.

14. MCKENNY, D. W., M. F. HUTCHINSON, J. L. KESTEVEN and L. A. VENIER. 2001. Canada's plant hardiness zones revisited using modern climate interpolation techniques. Canadian Journal of Plant Science 81:117-129.

15. MOSHER, J. A. and C. J. HENNY. 1976. Thermal adaptiveness of plumage color in Screech Owls. Auk 93:614-619.

16. RUTHERFORD, G. 1935. Chickadee Notes \#740 (a former column of the Winnipeg Free Press)

17. SETON, E. E. T. 1886. The birds of western Manitoba. Auk 3:145-156, 320-329.

18. SETON, E. E. T. 1908. Recent bird records for Manitoba. Auk 25:450-454.

19. TAVERNER, P. A. 1927. Some recent Canadian records. Auk 44:217-228.

20. MANITOBA AVIAN RESEARCH COMMITTEE. 2003. The Birds of Manitoba. Manitoba Naturalists Society, Manitoba Avian Research Committee, Winnipeg, Manitoba.

21. SETON, E. E. T. 1890. The birds of Manitoba. Proceedings of the U.S. National Museum 13:457643 [No. 841].

22. VANCAMP, L. F. and C. J. HENNY. 1975. The Screech Owl: Its Life History and Population Ecology in Northern Ohio. North American Fauna: 71. United States Department of the Interior Fish and Wildlife Service.

23. WALLEY, W. J. and C. F. CLYDE. 1996. Occurrence and breeding of the Eastern ScreechOwl north of the Riding Mountains, Manitoba. Blue Jay 54:89-100.

24. WARREN, F. J., E. BARROW, R. SCHWARTZ, J. ANDREY, B. MILLS and D. RIEDEL. 2004. Climate change impacts and adaptation: a Canadian perspective. Government of Canada, Climate Change Impacts and Adaptation Directorate, Ottawa, Ontario. 